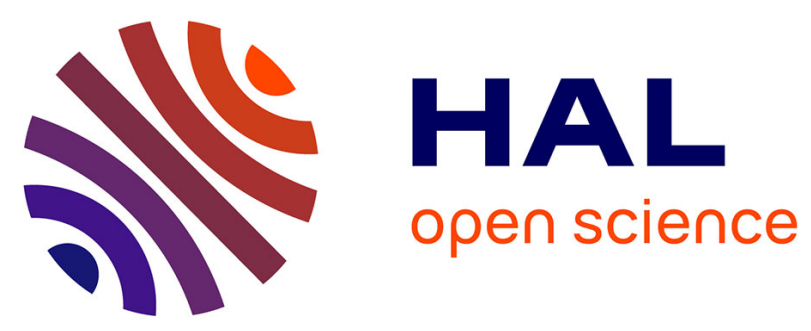

\title{
A passive autofocus system by using standard deviation of the image on a liquid lens
}

\author{
Pejman Rasti, Arko Kesküla, Henry Haus, Helmut Schlaak, Gholamreza
}

Anbarjafari, Alvo Aabloo, Rudolf Kiefer

\section{To cite this version:}

Pejman Rasti, Arko Kesküla, Henry Haus, Helmut Schlaak, Gholamreza Anbarjafari, et al.. A passive autofocus system by using standard deviation of the image on a liquid lens. SPIE Smart Structures and Materials + Nondestructive Evaluation and Health Monitoring, Mar 2015, San Diego, United States. 10.1117/12.2084198 . hal-02527959

\section{HAL Id: hal-02527959 \\ https://univ-angers.hal.science/hal-02527959}

Submitted on 2 Sep 2021

HAL is a multi-disciplinary open access archive for the deposit and dissemination of scientific research documents, whether they are published or not. The documents may come from teaching and research institutions in France or abroad, or from public or private research centers.
L'archive ouverte pluridisciplinaire HAL, est destinée au dépôt et à la diffusion de documents scientifiques de niveau recherche, publiés ou non, émanant des établissements d'enseignement et de recherche français ou étrangers, des laboratoires publics ou privés. 


\title{
A Passive Autofocus System by Using Standard Deviation Of the Image on a Liquid lens
}

\author{
Pejman Rasti ${ }^{\mathrm{a}}$, Arko Kesküla ${ }^{\mathrm{a}}$, Henry Haus ${ }^{\mathrm{b}}$, Helmut F. Schlaak ${ }^{\mathrm{b}}$, Gholamreza Anbarjafari ${ }^{\mathrm{a}}$, \\ Alvo Aabloo ${ }^{a}$, Rudolf Kiefer $^{\mathrm{a}^{*}}$ \\ ${ }^{a}$ Intelligent Materials and System Lab , Institute of Technology, University of Tartu, Nooruse 1, 50411 Tartu, \\ Estonia \\ ${ }^{\mathrm{b}}$ Institute of Electromechanical Design, Technical University Darmstadt, Merckstraße 25, 64283 Darmstadt, \\ Germany
}

\begin{abstract}
Today most of applications have a small camera such as cell phones, tablets and medical devices. A micro lens is required in order to reduce the size of the devices. In this paper an auto focus system is used in order to find the best positon of a liquid lens without any active components such as ultrasonic or infrared. In fact a passive auto focus system by using standard deviation of the images on a liquid lens which consist of a Dielectric Elastomer Actuator (DEA) membrane between oil and water is proposed.
\end{abstract}

Keywords: Sharpness Measurement, Liquid lens, Dielectric Elastomer Actuator, Standard deviation

*rudolf.kiefer@ut.ee; phone +3727374826; http://www.ims.ut.ee

\section{INTRODUCTION}

Cell phones or small cameras do not have enough free space to let users move rigid lenses in focal lengths ranges. In order to overcome the latter issue, [1] suggests using adaptive liquid lenses in small cameras, enabling them to focus without requiring extra room. On the other hand, classical methods using electric current for changing the shape of liquids consume lots of power. Auto-focus liquid lenses are of two sorts [2] [3]. The reflective type, being used as variable mirror, can be implemented in deigning reflector telescopes, where the transmissive type is based on convex-concave lens shape over immiscible fluids, with different refractive indices.

Using one or more fluids, unmoving, infinitely-variable liquid lenses can be produced for controlling the meniscus shape, which can be of liquid/liquid or liquid/air interface sorts. This way, the fluids could manipulate mechanically and electrically, and exploit the virtue of surface tension of the liquid [4]. When it comes to the mechanical method, the surfaced is displaced so as to adjust the lens' shape [5] [6], where in the case of electric method, ellectrowetting [7] [8] is the means by which the surface tension is adjusted. For some purposes, such as endoscopic medical imaging [9], fiber-optic telecommunication systems or micro cameras, liquid lenses can be used efficiently, which is based on the boundary between the two fluids, constructing a regular and smooth surface [2]. In this study, a Dielectric Elastomer Actuator (DEA) liquid lens with passive autofocus system is developed.

Autofocus systems can be either active or passive. In active ones, a couple of active components, such as ultrasonic components or infrared rays are embedded so as to assist the lens in reaching the desired position. In the sense of designing low-cost, thin and low-consumption applications, active systems entail some drawbacks. 
Passive systems, on the other hand, try to find the best focused lens position while obviating the need to incorporate active components [9]. A couple of image processing techniques, such as sharpness measurement can be utilized in the foregoing type of systems. A sharpness curve with respect to the lens position is shown in fig. 1, where the lens is in the best focused position, leading to the highest sharpness possible.

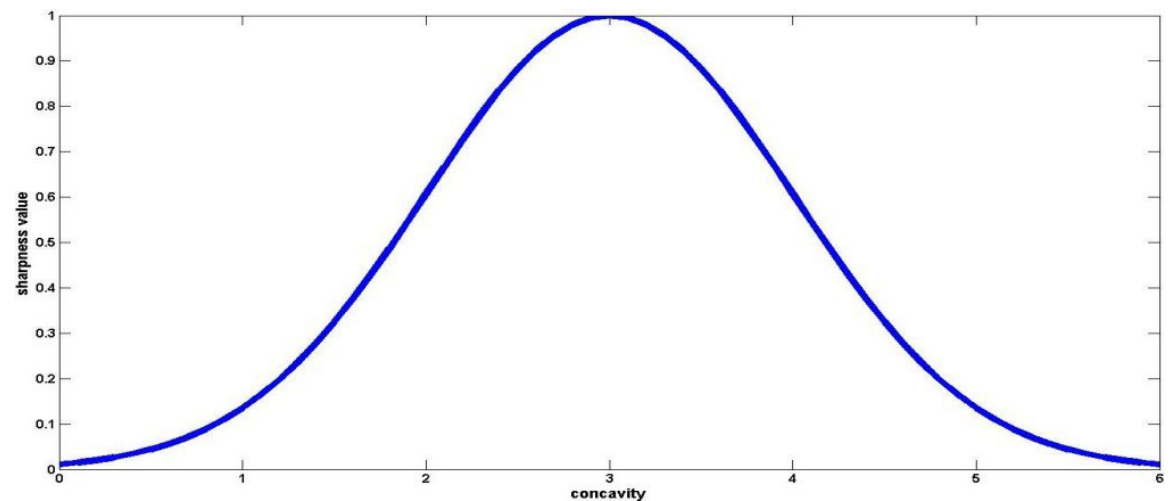

Fig. 1: The curve $\mathrm{C}$ of sharpness values versus lens position.

\section{DESIGN AND FABRICATION}

Two insoluble liquids and a membrane actuator are needed to fabricate the lens. In this case, an aqueous electrolyte and oil is used which separated with a membrane actuator, which had a hole with a diameter of $4 \mathrm{~mm}$ in the middle. A meniscus is formed by the liquids in correspondence of the central hole of the actuator as shown in Figure 2 [10]. The diameter and the shape of the meniscus is changeable by field-induced actuator deformation. The meniscus will work as a lens, if light passes through the hole. Focal length of the lens is adjustable by applying the different potential to membrane actuator which modifies the meniscus shape. Polyoxymethylene (POM) material is used to construct the liquid lens due to its resistance to all used chemicals and solvents [11]. A rectangular shape is considered for all parts of the initial device. The device is assembled easily in flexible design with actuator membranes of various sizes [10]. Figure 3 shows the prototype device

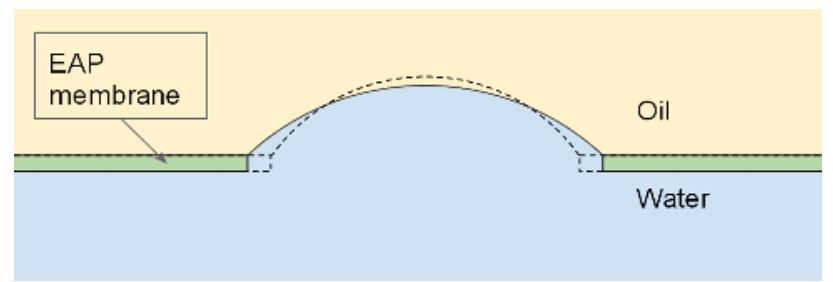

Figure 2: The working principle of an autofocus liquid lens based on mechanical lens change in applying membrane actuators [12]. 
Figure 3: The prototype device

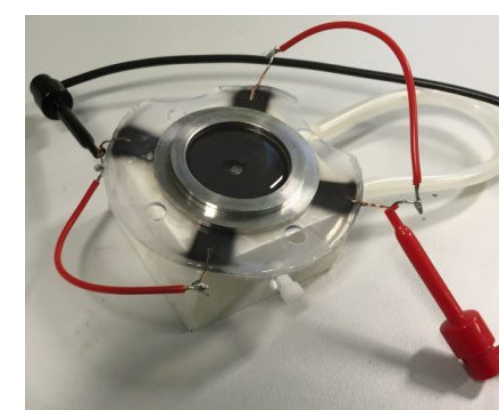

\subsection{Fabrication of DEA membranes}

DEA transform electric energy into mechanical work which consists of an elastic dielectric sandwiched between two compliant electrodes. Maxwell stresses are produced as a result of compression of the dielectric material sandwiched between the electrodes when a potential difference is applied to them. In this work a stack of DEA is used which fabricated by an automated fabrication process [12] [13].

First, spin coated substrate is used to keep a thin elastomeric film (P7670 - Wacker) fixed. The thickness of the film is dependent on the rotation speed, and could range from 5 and $100 \mu \mathrm{m}$ accordingly. Next, thermal heating is used in order to cure the elastomer. Afterward, using spraying, the compliant electrode (graphite powder) is deposited onto the dielectric. The foregoing process is iterated 100 times in order to stacked DEA membrane. A PDMS layer covers the $1^{\text {th }}$ cycle of the DEA membrane so as to make sure it will be encapsulated. Single-layermembrane prototypes are also built in order to compare their performance with the DESA.

\section{RESULTS AND DISCUSSION}

\subsection{Mathematical behavior of the DEA liquid lens}

The shape of the meniscus will change by changing in diameter of the hole. In fact, the diameter of the hole will contract by stretching the DEA due to pressure in dielectric elastomer $(p)$ which obtained by the following equation.

$$
p=\varepsilon_{0} \varepsilon_{r}\left(\frac{U}{T}\right)^{2}
$$

where the $\varepsilon_{0}$ is the vacuum permittivity $\left(8.85^{*} 10^{-12} A s / V m\right), \varepsilon_{r}$ is defined as dielectric constant of the polymer, $\mathrm{U}$ is applied voltage and $\mathrm{T}$ is the thickness of the elastomer film.

According to [14], the maximal applied voltage is varied from $1150 \mathrm{~V}$ to $2250 \mathrm{~V}$ depending on the layer thickness of DEA from $45 \mu \mathrm{m}$ to $100 \mu \mathrm{m}$ respectively. Also, depending on the applying voltage, the contraction of the hole is changed from 0 to $8 \%$. Despite of the range of voltage between 0 to 2250 for DEA, changing in the size of the membranes, initial curvature of meniscus, device configuration, hole diameter and focal length starting from $50 \mathrm{~V}$ to $600 \mathrm{~V}$. Figure 4 shows the contraction of the hole by increasing the applied voltage 


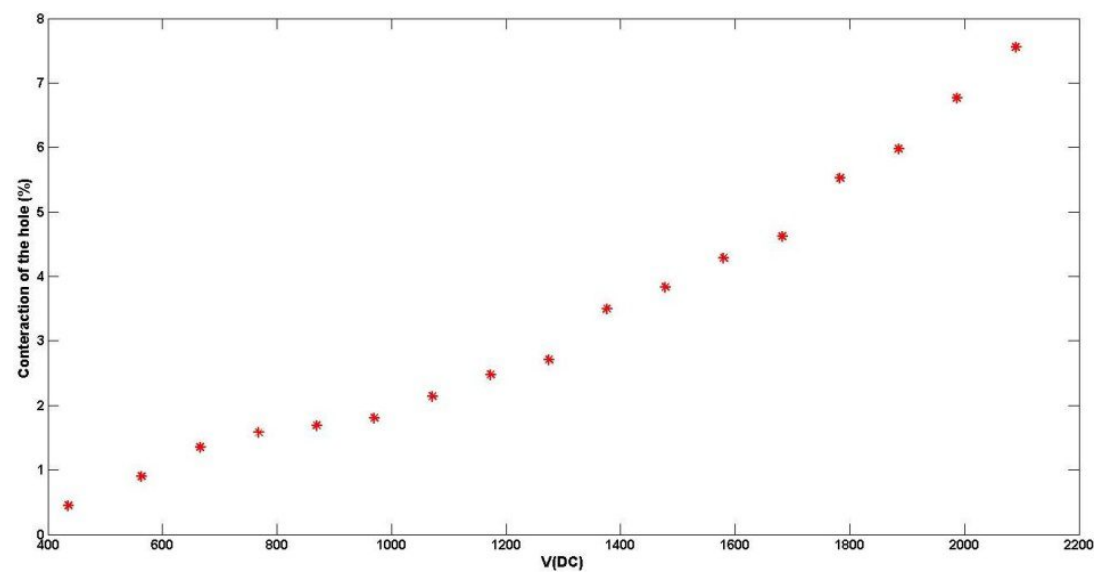

Figure 4: The contraction of the hole

\subsection{Sharpness Measurement}

In this work we need to recognize focus and out of focus images in order to find a proper voltage to apply to the membrane. One of the approaches to find focus image obtain by computing the standard deviation of the image. In this way a sample standard deviation of an image is computed by:

$$
\begin{aligned}
& s_{a}=\sqrt{\frac{1}{N-1} \sum_{m, n \in \Re}\left(a[m, n]-m_{a}\right)} \\
& =\sqrt{\frac{\sum_{m, n \in \Re} a^{2}[m, n]-N m_{a}^{2}}{N-1}}
\end{aligned}
$$

Where $\mathfrak{R}$ is a region with $\mathrm{N}$ pixels. In fact ${ }{ }_{a}$ is an estimate of $\sigma_{a}(\Sigma)$ of the underlying brightness probability distribution.

The proposed system is divided to some phases. In the first phase, a photo is captured by the image acquisition device equipped with a DEA liquid lens. Then sharpness of the captured image is computed to find the amount of edge information. In the second phase the amount of applied voltage to the membrane actuator is increased in order to change in the shape of the meniscus. The number of edges of the second photo which taken afte deformation of the meniscus is calculated and compared with the earlier one. In the third phase, according to the result of sharpness comparing of taking images, the applied voltage is increased or decreased to take the next photo. The process is iterated till the number of the edges in the photo decreases regardless of the variations of the applied voltage. Figure 5 shows the scheme of the proposed method.
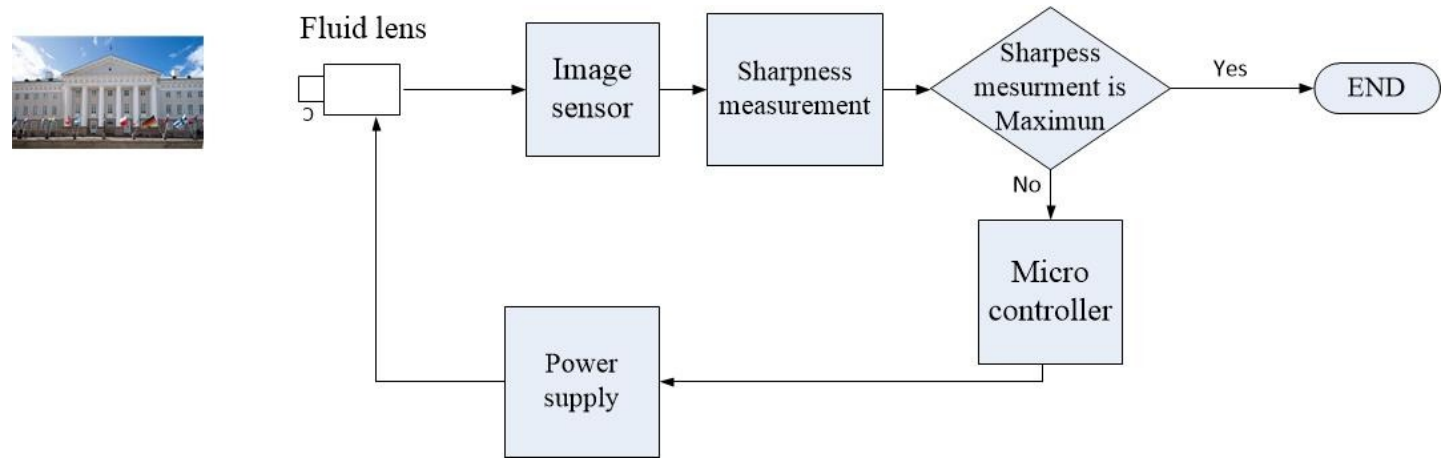

Figure 5: The scheme of the proposed method 
As we expected Figure 6 shows which the size of focal length is decreased by increasing the applying voltage.

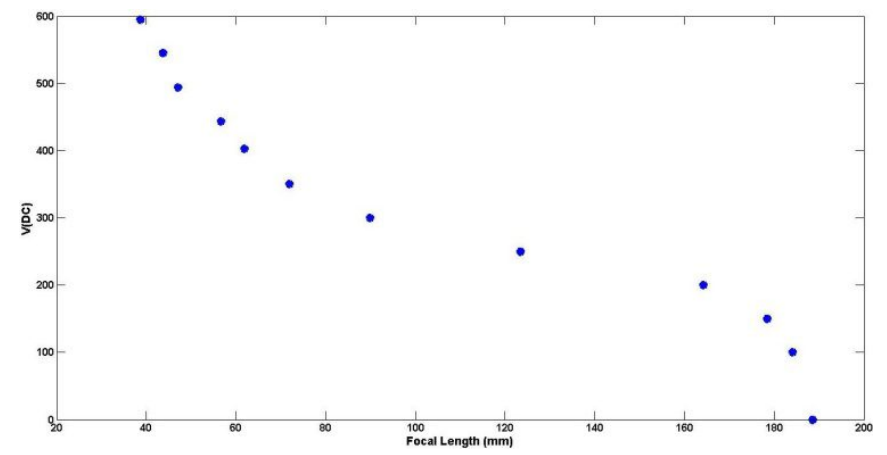

Fig. 6 : The changing of the focal length

\section{Conclusions}

In this work a passive autofocus system for a liquid lens with Dielectric Elastomer Actuator (DEA) was presented which can easily achieve the function of auto focus without any active component such as ultrasonic or infrared in comparison with the conventional active focus system. To implement the technique we used a liquid lens with DEA membrane and a system to measure the sharpness of the image. The proposed method found the best position of the lens by controlling the voltage which is applied to the membrane.

\section{ACKNOWLEDGEMENTS}

The research was supported by the European Union through the European Social Fund (MTT76) the European Scientific Network for Artificial Muscles (ESNAM, ECOST-STSM-MP1003), partly supported by ERDF program "Estonian higher education information and communications technology and research and development activities state program 2011-2015 (ICT program)" and Estonian Research Council grant PUT (PUT638).

\section{REFERENCES}

[1] S. Kuiper, B. H. Hendriks, L. J. Huijbregts, A. Hirschberg, C. A. Renders and M. A. J. van As, "Variablefocus liquid lens for portable applications," Proc SPIE, pp. 100 - 109, 2004.

[2] S. Kuiper and B. H. w. Hendriks, "Variable-focus liquid lens for miniature cameras," APPLIED PHYSICS LETTERS, vol. 85, pp. 1128 - 1130, 2004.

[3] H. -T. Hsieh, H. C. Wei, M. H. Lin, W. Y. Hsu, Y. C. Cheng and G. D. John Su, "Thin autofocus camera module by a large-stroke micromachined deformable mirror," Optics Express, vol. 18, pp. 11097-11104, 2010.

[4] F. Wippermann, P. Schreiber, A. Bräuer and P. Craen, "Bifocal liquid lens zoom objective for mobile phone applications," Proc. SPIE 6501, 2007.

[5] C. B. Gorman, H. A. Biebuyck and G. M. Whitesides, "Control of the Shape of Liquid Lenses on a 
Modified Gold Surface Using an Applied Electrical Potential across a Self-Assembled Monolayer," Langmuir, vol. 11, p. 2242-2246, 1995.

[6] R. Pelrine, R. Kornbluh, Q. Pei, S. Stanford, S. Oh and J. Eckerle, "Dielectric elastomer artificial muscle actuators: toward biomimetic motion," in SPIE's 9th Annual International Symposium on Smart Structures and Materials, 2002.

[7] B. Berge and J. Peseux, "Variable focal lens controlled by an external voltage: An application of electrowetting," The European Physical Journal , vol. 3, no. 2, pp. 159-163, 2000.

[8] L. Saurei, G. Mathieu and B. Berge, "Design of an autofocus lens for VGA 1/4-in. CCD and CMOS sensors," Proc. SPIE 5249, Optical Design and Engineering, pp. 288-296, 2004.

[9] M. Subbarao and J. K. Tyan, "The Optimal Focus Measure for Passive Autofocusing and Depth-fromFocus," in Proceedings of SPIE conference on Videometrics IV, 1995.

[10] H. Kiveste, H. Haus, D. Gatti, H. F. Schlaak, A. Aabloo and R. Kiefer, "Autofocus liquid lens device with implementation of dielectric elastomer actuators," in International Conference and Exhibition on New Actuators and Drive Systems, Bremen, 2014.

[11] H. Kiveste, "Liquid lens Device Construction And Actuator Performance Based On Electroactive Polymers," Master Thesis, 2013.

[12] P. Lotz, M. Matysek and H. Schlaak, "Fabrication and Application of Miniaturized Dielectric Elastomer Stack Actuators," Mechatronics, IEEE/ASME Transactions on, vol. 16, pp. 58-66, 2011.

[13] H. F. Schlaak, M. Jungmann, M. Matysek and P. Lotz, "Novel multilayer electrostatic solid state actuators with elastic dielectric," Proc. SPIE 5759, Smart Structures and Materials, 2005.

[14] H. Kiveste, "Liquid lens device modification with implementation of dielectric elastomer actuators," 2013. 